\title{
Cytogenetic studies in three cases of hermaphroditism in the Spanish goat breed Murciano-Granadina
}

\author{
NL Lopez ${ }^{1}$, M Barberan ${ }^{2}$, MV Arruga ${ }^{1}$ \\ 1 Facultad de Veterinaria, Laboratorio de Citogenética; and \\ 2 Dept de Patología Animal, Miguel Servet, 177, 50013 Zaragoza, Spain
}

(Proceedings of the 9th European Colloquium on Cytogenetics of Domestic Animals; Toulouse-Auzeville, 10-13 July 1990)

goats / cytogenetics / intersexuality

\section{INTRODUCTION}

Studies on detection, anatomy and cytogenetics of intersex goats have been described in several breeds in relation to the absence of horns in males (Padeh et al, 1965; Ilbery and Williams, 1967; Cribiu and Lehrm, 1986; Ramadan and El-Hassan, 1988; Moreno-Millán and Rodero, 1988). In general, the presence or absence of horns can be attributed to the action of two alleles at an autosomal locus, with polled (P) being dominant to horned (p).

In goats, horned (pp) or heterozygous for polled $(\mathrm{Pp}) \mathrm{XX}$ individuals are normal females. But all XX goats that are homozygous for the polled allele are intersexes. In addition, a proportion of $\mathrm{XY}$ goats that are homozygous for the polled allele are sterile.

In the present paper, we describe comparative studies on the cytogenetic and anatomic configuration of 3 cases of intersexuality in goats belonging to the Murciano-Granadina breed.

\section{MATERIALS AND METHODS}

Three intersex animals were analyzed cytogenetically by preparation of leukocyte cultures from peripheral blood, according to the method of Moorhead et al (1960) with several modifications. R-banding (Di Berardino et al, 1987) and G-banding (Francke and Ollivier, 1978) were carried out to identify the chromosome pairs.

Sex chromosomes were studied in these animals by electron microscopy according to the method of Goyanes and Mendez (1981). At postmortem, bone marrow, gonad, kidney and skin were sampled for tissue cultures and cytogenetic examination. At the same time, the reproductive tracts were dissected and examined macroscopically 
and the specimens were fixed in Bouin's fluid and the sections were stained with hematoxylin and eosin for histological studies.

\section{RESULTS}

Two of the animals $(60, \mathrm{XX}$ and $60, \mathrm{XY})$ were polled and one $(60, \mathrm{XY})$ was horned, however, all 3 were externally considered females. Mosaicism, chimerism or chromosome aberrations were not observed in any of the animals (fig $1 \mathrm{a}, \mathrm{b}$ ).
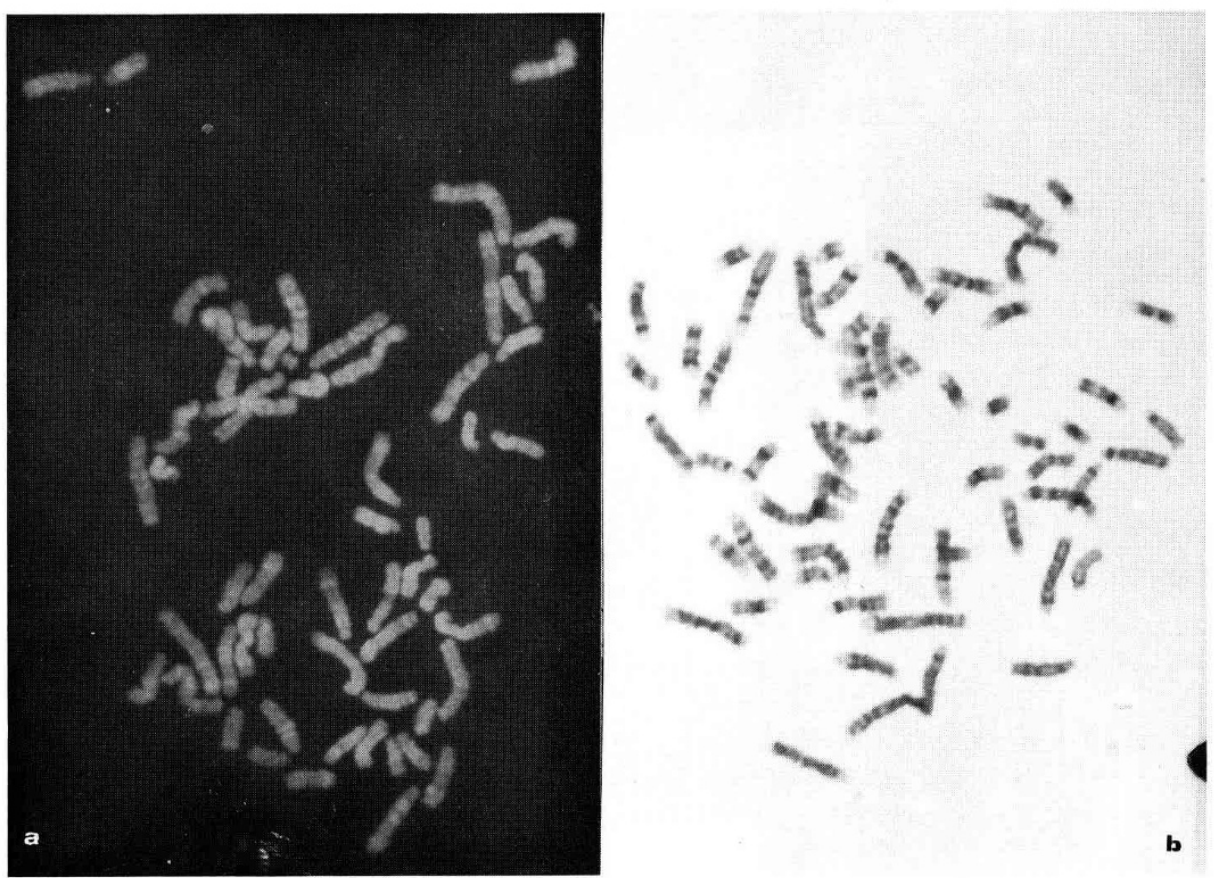

Fig 1. a. R-banded metaphase in a male goat $60, X Y$. b. G-banded metaphase in a female goat $60, \mathrm{XX}$.

The sex chromosomes studied by electron microscopy showed a metacentric morphology in the $\mathrm{Y}$ chromosome and subtelocentric morphology in the $\mathrm{X}$ chromosome, with a small short arm (fig $2 a$ ).

A summary of the macroscopic findings on the reproductive tracts in these animals is given in table $\mathrm{I}$. All cases possessed similar external reproductive organs and presented a hypertrophic clitoris protruding from a pseudovagina (figs $2 \mathrm{~b}$ and $3 a)$. Although the degree of masculinization varied among them, their external genitalia were essentially of the female type. No scrotum was observed, although 2 testes were detected in the inguinal region of the two 60,XY animals.

Only 2 animals, the $60, \mathrm{XX}$ and one of the $60, \mathrm{XY}$, were dissected for histological and anatomic analysis. In the male 60,XY, the testes had epididymides and its 


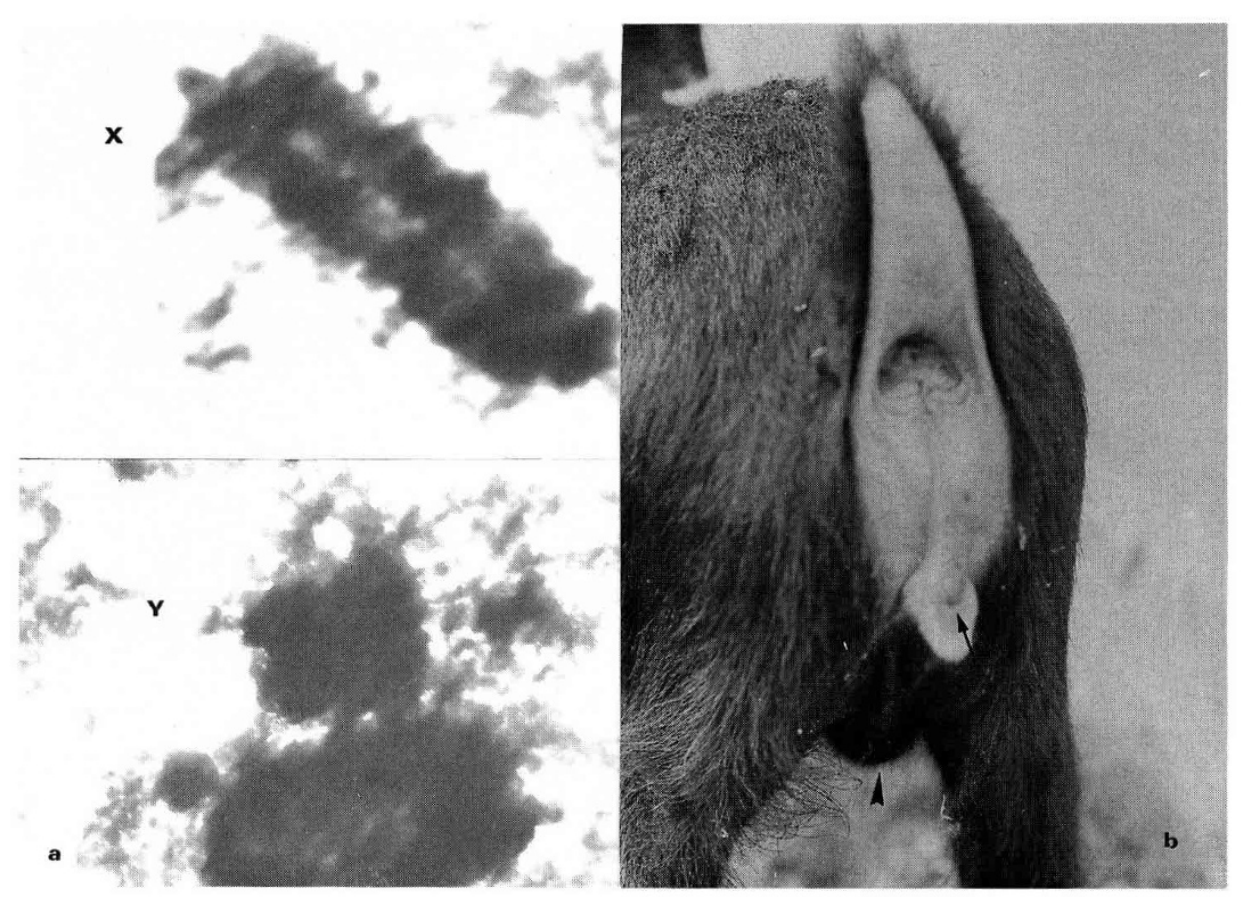

Fig 2. a. Electrophotomicrograph of the $X$ and $Y$ chromosomes in an intersex male $60, X Y$ $(\times 20000)$. b. External sexual organs in the female $60, \mathrm{XX}$ with a penis-like clitoris $(\rightarrow)$, and a unilateral scrotum $(\triangleright)$.

Table I. Summary of the macroscopic structure and histology of the reproductive tracts and the gonads in 3 cases of intersexuality in goats.

\begin{tabular}{lcccccc}
\hline Animal & Scrotum & Testes & Epididymides & Seminal vesicles & Uterus & $\begin{array}{c}\text { Pesudovagina } \\
+ \text { clitoris }\end{array}$ \\
\hline $60, \mathrm{XX}$ & + & 2 & 2 & + & + & + \\
$60, \mathrm{XY}$ & - & 2 & 2 & + & + & + \\
$60, \mathrm{XY}$ & - & 2 & - & - & - & + \\
\hline
\end{tabular}

deferent ducts had an interrupted segmental form. Emerging from each epididymis were 2 ducts ending in an aplastic uterus. Seminal vesicles were also present (fig 3b). The 60,XX animal had a unilateral scrotum associated with the right testis. The left testis was intra-abdominal. Both testes were atrophic with hypoplastic epididymides. Two tubes emerged from the epididymides. One ended as an ampulla in a uterus of $8.4 \times 2.8 \mathrm{~cm}$, which, in turn ended in one cylindrical tube connected to the urethra. Two organs, identified as seminal glands, were found on the distal wall of the uterus. 


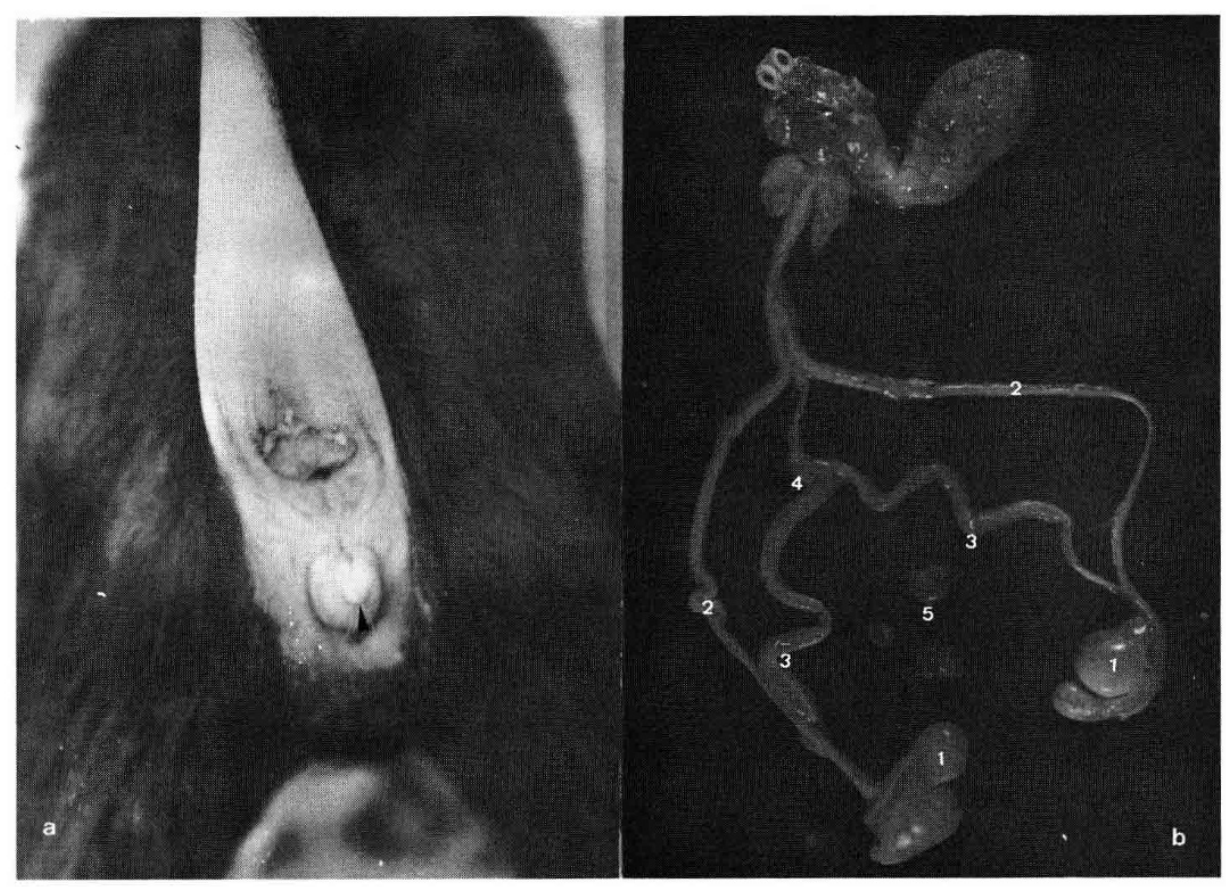

Fig 3. a. External sexual organs in the male $60, \mathrm{XY}$, with a penis-like clitoris protruding from a pesudovagina $(\mathbf{A})$. b. The sexual organs dissected in the same animal: 1: testes; 2: deferent ducts; 3: uterine ducts; 4: uterus; 5: seminal vesicles (separated from the preparation).

Histological studies of the clitoris of the $60, \mathrm{XX}$ animal showed a penis-like structure with connective and cavernous tissue. The testes exhibited neither meiotic activity nor germ cells in the dissected $60, \mathrm{XX}$ and $60, \mathrm{XY}$ animals.

\section{DISCUSSION}

According to the results obtained, the animals studied can be defined as 'pseudohermaphrodites'. The association between intersexuality and polledness in goats is summarized in table II. Our results are in agreement with those of Nicholas (1987), except for the 60,XY horned male described. The reason for this association and the genetic determination are not yet known, in spite of several models having been proposed to explain them (Muller et al, 1979; Kent et al, 1986; Fredga, 1988).

The discovery of repetitive $\mathrm{Bkm}$ (banded krait minor satellite) sequences, associated with the male-determinant region on the $\mathrm{Y}$ chromosome in several species (human, mouse and horse, in particular) (Kent et al, 1988), has led to the elaboration of a hypothesis as to the implication of these sequences in chromosome arrangements (deletions or translocations). Consequently, the studies of these 'pseu- 
Table II. The association between intersexuality and polledness in goats.

\begin{tabular}{cccc}
\hline Sex chromosomes & \multicolumn{3}{c}{ Genotype at the polled locus } \\
\cline { 2 - 4 } & $P P$ & $P p$ & $p p$ \\
\hline $\mathrm{XX}$ & polled & polled & horned \\
& intersex & female & female \\
$\mathrm{XY}$ & polled & polled & horned \\
& male & male & male \\
\hline
\end{tabular}

dohermaphrodites' are of great theoretical importance, because of the light they shed on the mechanisms of sexual differentiation in mammals.

\section{REFERENCES}

Cribiu EP, Lehrm C (1986) Caryotype normal et anomalies chromosomiques de la chèvre domestique (Capra hircus) Recl Méd Vét 162, 163-167

Di Berardino D, Rønne M, Burguete I, Lioi MB, Taibi D, Matassino D (1987) R-banding pattern of the prometaphase chromosomes of the goat. $J$ Hered 78, 225-230

Francke U, Ollivier N (1978) Quantitative analysis of high-resolution trypsin-giemsa bands on human prometaphase chromosomes. Hum Genet 45, 137-165

Fredga K (1988) Aberrant chromosomal sex-determining mechanism in mammals with special reference to species with XY females. Philos Trans $R$ Soc London B 322, 83-95

Goyanes VJ, Mendez J (1981) Karyotyping chromosomes by electron microscopy. Condensation-inhibition of G-bands in human and Chinese hamster chromosomes by a BrdUHoescht 33258 treatment. Cancer Genet Cytogenet 4, 45-51

Ilbery PLT, Williams D (1967) Evidence of the freemartin condition in the goat. Cytogenetics $6,276-285$

Kent MG, Shoffner RN, Buoen L, Weber AF (1986). XY sex-reversal syndrome in the domestic horse. Cytogenet Cell Genet 42, 8-18

Kent MG, Elliston KO, Shroeder W, Guise KS, Wachtel EE (1988) Conserved repetitive DNA sequences $(\mathrm{Bkm})$ in normal equine males and sex-reversed females detected by in situ hybridization. Cytogenet Cell Genet 48, 99-102

Moorhead PS, Nowell PC, Mellman WJ, Battips DA, Hungerford DM (1960) Chromosome preparations of leukocytes cultured from human peripheral blood. Exp Cell Res 20,613-616 Moreno-Millan M, Rodero A (1988) Estudio citogenético de cabras hermafroditas de la raza Malaguena. Arch Zootec 37, 97-102

Muller U, Zenzes MT, Wolf V (1979) Appearance of H-W (H-Y) antigen in the gonads of oestradiol, sex-reversed male chicken embryos. Nature 280, 142-144

Nicholas FN (1987) Veterinary Genetics. Clarendon Press-Oxford University Press, UK Padeh B, Wysoki M, Ayalon N, Soller B (1965) An XX/XY hermaphrodite in the goat. Isr J Med Sci 5, 1008-1012

Ramadan RO, El Hassan AM (1988) Intersexuality in goats. New Zealand Vet $J 36,120$ 124 